Talent does not stem from our genes alone, argues science writer David Shenk in The Genius in All of Us (Doubleday, 2010). Favouring nurture over nature, he examines the science of genetics, cognition and human development and concludes that top performers are moulded by hard work and circumstance, not their biological blueprint. Although the idea of preprogrammed success has been promulgated for decades, Shenk shows instead that human intelligence and talent are abundant resources that society should tap into.

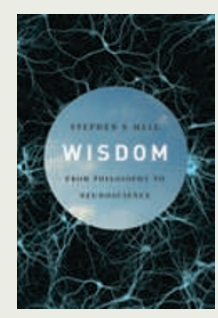

Wisdom is the theme explored by Stephen Hall in his interweaving of neuroscience and philosophy. He explains in Wisdom (Knopf, 2010) how thinking about intellect, emotion and ethics has influenced social change over the centuries. In the past 50 years, scientific advances have given us insight into decisionmaking, emotion and cognition, compassion and empathy. Yet chance and stress still alter the degree to which we can apply our wisdom in the world.

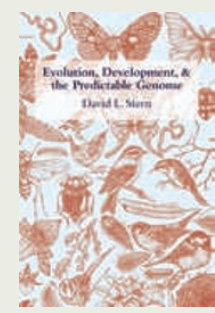

Evolutionary biologist David Stern argues in his book that evolution and development are inextricably intertwined, concluding

that the evolution of genomes is foreseeable. In Evolution, Development, $\&$ the Predictable Genome (Roberts, 2010), he focuses on the individual steps of evolutionary change, examining how certain genetic and developmental traits are favoured within populations. He explains how new data are emerging that will allow us to test patterns of biological diversity.

\title{
Smithsonian on human origins
}

A permanent exhibition exploring what it means to be human opened last month at the Smithsonian National Museum of Natural History in Washington DC. The US\$20.7-million David H. Koch Hall of Human Origins depicts how human traits evolved out of our ancestors' struggle to survive changes in climate over the past 6 million years.

The exhibit focuses on six evolutionary milestones of early humans: walking upright, experimenting with new tools and foods, changing body sizes and shapes, developing bigger brains, increasing social networks and communicating using symbols.

Visitors can compare their stride to the 3.6-million-year-old footsteps of Australopithecus afarensis. This species of hominin, which includes the fossilized partial skeleton named Lucy, walked upright and climbed trees, adapting as climate fluctuated between wet and dry, cool and warm. Walking on two legs helped A. afarensis to pick fruit and left their hands free to carry babies. In a striking comparison of body size, a child skeleton of Homo erectus named Turkana Boy stands next to the adult composite skeleton of Homo neanderthalensis, which is only marginally taller. Whereas $H$. erectus was adapted to hot climates, having a long, narrow body for dissipating heat,
David H. Koch Hall of Human Origins Smithsonian National Museum of Natural History, Washington DC Permanent exhibition

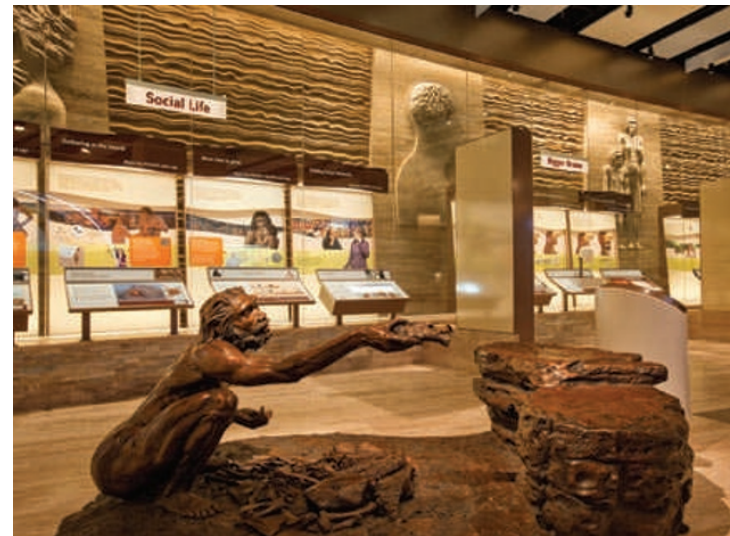

The permanent exhibit casts climate change as the driver of human evolution.

that transforms your picture into a portrait of your prehistoric ancestor.

Seven reconstructed busts - including that of a 1-metre-tall female 'hobbit', Homo floresiensis, from Indonesia and a male $H$. neanderthalensis - allow a more personal connection than the blank gazes offered by their skulls, 76 of which are bolted to a huge wall display, representing 15 species. To determine whether they could turn up the corners of the mouth like modern humans, "we looked at where smile $H$. neanderthalensis had a shorter, wider body to conserve heat in colder European climes.

On show are tools from as early as 2.6 million years ago that allowed the killing of large animals for food. The use of hand axes in the Palaeolithic for chopping, cutting and scraping began about 1.7 million years ago. A million years later, early humans began gathering at the hearth to share food, find safety from predators and build social networks. As they encountered new environments and faced new challenges, their brains got bigger, according to a display that correlates climate fluctuations with expanding brain size.

Another display encourages visitors to feel the sloping face of a 2.5-million-year-old Australopithecus africanus skull, balance a pencil on the prominent brow ridges of a 350,000-year-old Homo heidelbergensis skull and compare both with the face of a modern human. People can practise forensic anthropology with the most precious fossil in the collection: 130 bones of the only Neanderthal skeleton housed in the United States. He was a 40 -something male, found in Iraq, who had arthritis and probably died from a stab wound to the chest. The most crowded part of the exhibit is the least scientific: a photo booth muscles attach", says Rick Potts, director of the Smithsonian's Human Origins Program. "Their smiles look different from ours and are more like the grimace of a chimpanzee."

Above the skulls, a label reads: "Fossils of more than 6,000 individuals discovered so far. More than a dozen species identified. Only our species, Homo sapiens, remains." The exhibition gives constant reminders that life is precarious - whether through suspenseful music, in a short video playing the chimp-like squeals of an early human attacked by a leopard or in displays of hominin bones etched by crocodile teeth or eagle talons. Although we have survived, "our species has also been fragile”, says Potts. H. sapiens almost became extinct 70,000 years ago when vast swings in climate reduced the population to a few thousand breeding adults. Potts adds: "Our intentions, the decisions we make, make a difference."

Janet Fang is a news intern at Nature.

\section{Correction}

In the picture caption of the Book Review 'Two views of collapse' (Nature 463, 880-881; 2010), we wrongly stated that Chaco Canyon's society existed in the first century. It should have read 'eleventh century'. 